\title{
Obituary
}

\section{Sir Lawrence Bragg}

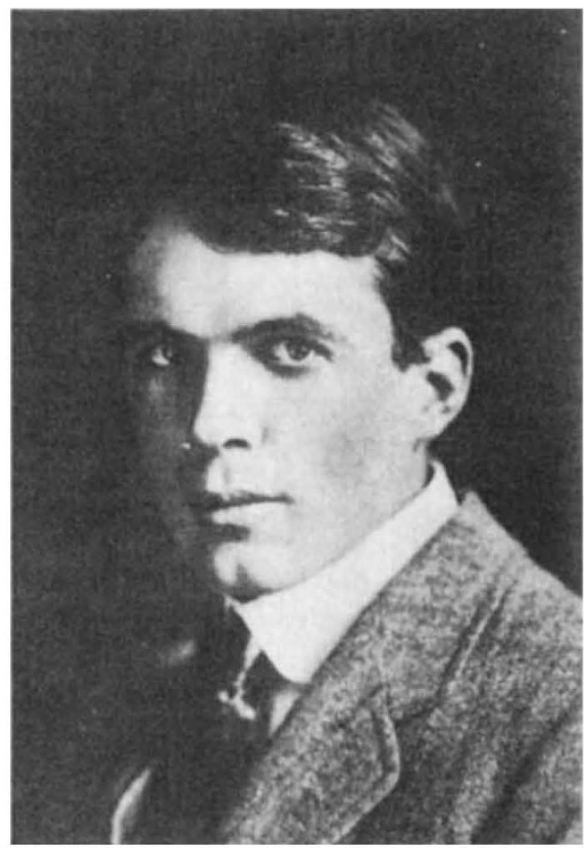

Fig. 1 William Lawrence Bragg as a young graduate at Cambridge. (By courtesy of the Nobel Foundation.)

Sir LaWrence BragG, who died on July 1 aged 81 , had the unique distinction of having himself created the science to which he devoted his life's work, and lived long enough to experience its revolutionary impact, first on inorganic chemistry and mineralogy, then on metallurgy, and finally on organic chemistry and biochemistry. At the same time X-ray analysis itself advanced from the ingenious puzzle-solving of the early pioneers to the almost blindfold automation of the present day.

Röntgen discovered X-rays when Bragg was five years old, and von Laue, Friedrich and Knipping demonstrated $\mathrm{X}$-ray diffraction by crystals in the spring of 1912, when Bragg was taking his physics degree at Cambridge (Fig. 1). Von Laue, who had predicted the effect, also succeeded in developing a theory of scattering from a three dimensional lattice, but he assumed that the crystal of zincblende used for diffraction had a primitive cubic lattice, and therefore could not explain why spots corresponding to certain indices were present while others with closely related indices were absent. He speculated whether the diffraction effects had arisen from fluorescence excited in the atoms of the crystal by the "aperiodic pulses" of the primary radiation or whether five prominent wavelengths pre-existing in the primary radiation had been separated out to produce the different diffraction spots.

Bragg's father, then Professor of Physics at Leeds, heard of the German work in the summer of 1912 and discussed it with his son, who set about re-interpreting the X-ray pictures of zincblende published by the Munich group. Within a few weeks he presented the correct answer to a meeting of the Cambridge Philosophical Society. The German group had noticed that spots which were round when their photographic plate was close to the crystal became elliptical as the plate was moved further away. By a remarkable feat of imaginative insight Bragg realized that such a focusing effect would arise if the X-rays were reflected by successive atomic planes (Fig. 2), and he reformulated von Laue's conditions for diffraction into what became known as Bragg's Law, which gives a direct relationship between the crystal structure and its diffraction

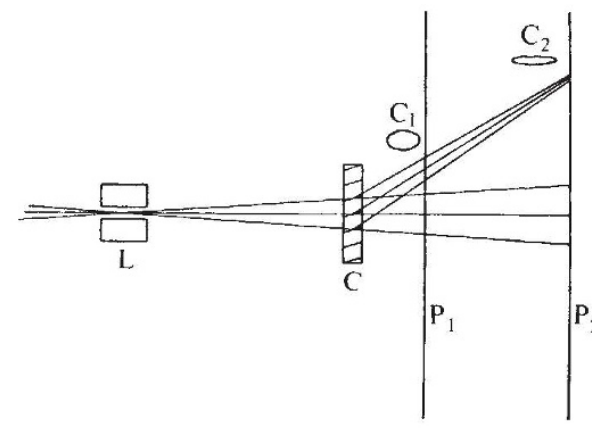

Fig. 2 Bragg's interpretation of the focusing of the diffracted spots observed by von Laue, Friedrich and Knipping which led to the formulation of Bragg's law: $n \lambda=2 \operatorname{disin} \theta$. L, Lead screen; $C$, crystal; $P_{1} P_{2}$, positions of photographic plate; $C_{1} C_{2}$, cross sections of pencil of rays at $\mathbf{P}_{1} \mathbf{P}_{2}$. (From Proc. Camb. Phil. Soc., 17, No. 1,$43 ; 1913$.)

pattern. Bragg then recognized that sets of parallel lattice planes would select from a continuous spectrum (or pulse, as he called it) those wavelengths which corresponded to integral multiples of the path difference between reflexions from successive atomic planes, so that each Laue spot would be made up of several harmonics of some selected wavelength. Finally, he demonstrated that the presence of spots with certain combinations of indices, and the absence of others, could be accounted for by assuming a facecentred rather than a primitive cubic lattice.

Why did this twenty-two year old student succeed in correctly interpreting the diffraction pattern predicted and discovered by an accomplished theoretician eleven years his senior? Bragg himself modestly attributes it to a "concatenation of fortunate circumstances" but his paper soon convinces you that its success owed more to Bragg's astute powers of penetrating through the apparent complexities of physical mechanisms to their underlying simplicity.

This first paper was quickly followed by another, written in collaboration with his father, on their newly developed X-ray spectrometer, and a third, written by himself alone, solving the structure of common salt and showing how the Laue pictures of several other simple minerals could be indexed. There follows the structure of diamond, solved, as he relates, largely by his father, and the structures of fluorspar, zincblende, iron pyrites, calcite and dolomite solved by himself alone. Finally, on July 16, 1914, he communicated a paper on the structure of metallic copper. In view of this published record and the fact that for most of the relevant period the father was at Leeds and the son at Cambridge, it seems hardly believable that the scientific public tended to attribute most of the credit for these discoveries to his father, sometimes with the undertone that the son had cashed in on the father's success. The son must have suffered a great deal from these thoughtless judgments.

The outbreak of the First World War put an end to further research. Bragg joined the cavalry and was soon detailed to help in the development of sound ranging for the location of enemy batteries. At first he could not separate the report of the gun from the noise of the projectile travelling at supersonic speed. Then he suddenly spotted that the firing of the gun gave rise to a pressure wave, a "rush of air" as he called it, which he was able to detect by its momentary cooling of a hot wire. This simple device made an important contribution to victory.

He resumed his research when, aged twenty-nine, he was appointed Rutherford's successor as professor of physics at Manchester. His early research had replaced the concept of the inorganic molecule by the new one of a three dimensional array of close-packed and electrically compensating ions. The next step was a reformulation, on a structural basis, of the chemistry of the silicates. For example, diopside had been assigned the formula $\mathrm{CaMg}\left(\mathrm{SiO}_{3}\right)_{2}$, but $\mathrm{B}$. E. Warren and Bragg discovered that there was no such thing as an $\mathrm{SiO}_{3}^{2-}$ ion. The structural units consisted of $\mathrm{SiO}_{4}$ tetrahedra as in quartz; these shared corners so that they formed infinite chains bound to their neighbours 
on all sides by $\mathrm{Ca}$ and $\mathrm{Mg}$ ions. The varying properties of the many different silicates were found to be a consequence of the ways in which $\mathrm{SiO}_{4}$ tetrahedra can be linked, sharing corners, edges or faces, and forming long chains as in asbestos, sheets as in mica, or three dimensional networks as in the feldspars, so brilliantly solved by W. H. Taylor. Silicates make up the bulk of the Earth's crust, and Bragg was proud that he and his associates had explained their properties on the basis of their atomic structure. The results of the Manchester school also led Pauling to formulate general rules for the structures of inorganic crystals: atomic arrangements are governed by the ratios of the ionic radii and are stable only if all charges are locally compensated.

When the main structural principles of the silicates had been discovered, Bragg's interest turned to metals. He did not actually solve any metal structure himself, but became absorbed in the X-ray analysis of alloys by A. J. Bradley and others in the Manchester laboratory. His greatest papers of that period are those with E. J. Williams on orderdisorder phenomena. For example, in brass at room temperature, copper occupies the corners and zinc the centres of a cubic lattice, but when heated they become more randomly distributed over the two sites until at a critical temperature all long range order ceases abruptly. Why does the approach to disorder suddenly become catastrophic? Bragg and Williams argued that "the decrease in order lessens the forces which tend to keep an atom in its 'right' place, since when disorder is nearly complete the criterion between 'right' and 'wrong' tends to vanish. The effects of increasing thermal agitation and lessening distinction between right and wrong so interact that on approaching a critical temperature the order drops rapidly to zero". Their physical explanation of the catastrophic approach to disorder in alloys later formed the basis for the interpretation of other cooperative phenomena in solids.

I first met Bragg in 1939 at the height of his metallic period, and he put me to work on the X-ray microscope, a neat optical device which he had just invented for the summation of two dimensional Fourier series. He was also keenly interested in my X-ray pictures of haemoglobin, but he did not actually work on the problem until the early fifties when he deduced the correct shape of the haemoglobin molecule from my data. Shortly afterwards he introduced the principle of minimum wavelength which limits the combination of signs in the Fourier transform of a molecule of given size. In the event, the limitations proved insufficient to solve the phase problem in haemoglobin, but the principle later helped D. L. D. Caspar and Rosalind Franklin to solve it in a radial projection of tobacco mosaic virus.
Bragg's last original paper concerned the determination of phase angles by the method of multiple isomorphous replacement with heavy atoms. In monoclinic crystals such as myoglobin or haemoglobin the location of the heavy atoms in the centrosymmetric projection was straightforward, but the determination of their third coordinate, which is not related to any symmetry element in the crystal, posed a difficult problem. Bragg devised an elegant method, based on a principle of physical optics, of deducing these coordinates from the changes in intensity produced by different isomorphous replacements in the same reflexions. As the correct values of the phase angles of several myoglobin reflexions emerged from his calculations he realized that the problem of protein structure, that seemingly hopeless venture which he had backed against all odds for the past eighteen years, could now be solved, and tears of emotion streamed down his face. Bragg's coordinates served as an independent check for those which Kendrew and his collaborators deduced from Patterson syntheses. K. C. Holmes recently used his method to find the heavy atom coordinates in tobacco mosaic virus.

I have tried to summarize Bragg's many other contributions to science in a table which also shows the periods of his different activities in various places (Table 1). The sciences have developed so much faster than the arts. If we think of Bragg as an artist and compare him to, say, Giotto, it is as though he had himself invented three dimensional representation, and then lived through all the styles of European painting from the Renaissance to the present day, to be finally confronted by computer art.

So often men of genius were hellish to live with, but Bragg's creativity was sustained by a happy home life; typically one would find him tending his garden, with Lady Bragg, children and grandchildren somewhere in the background, and before getting down to business he would proudly demonstrate

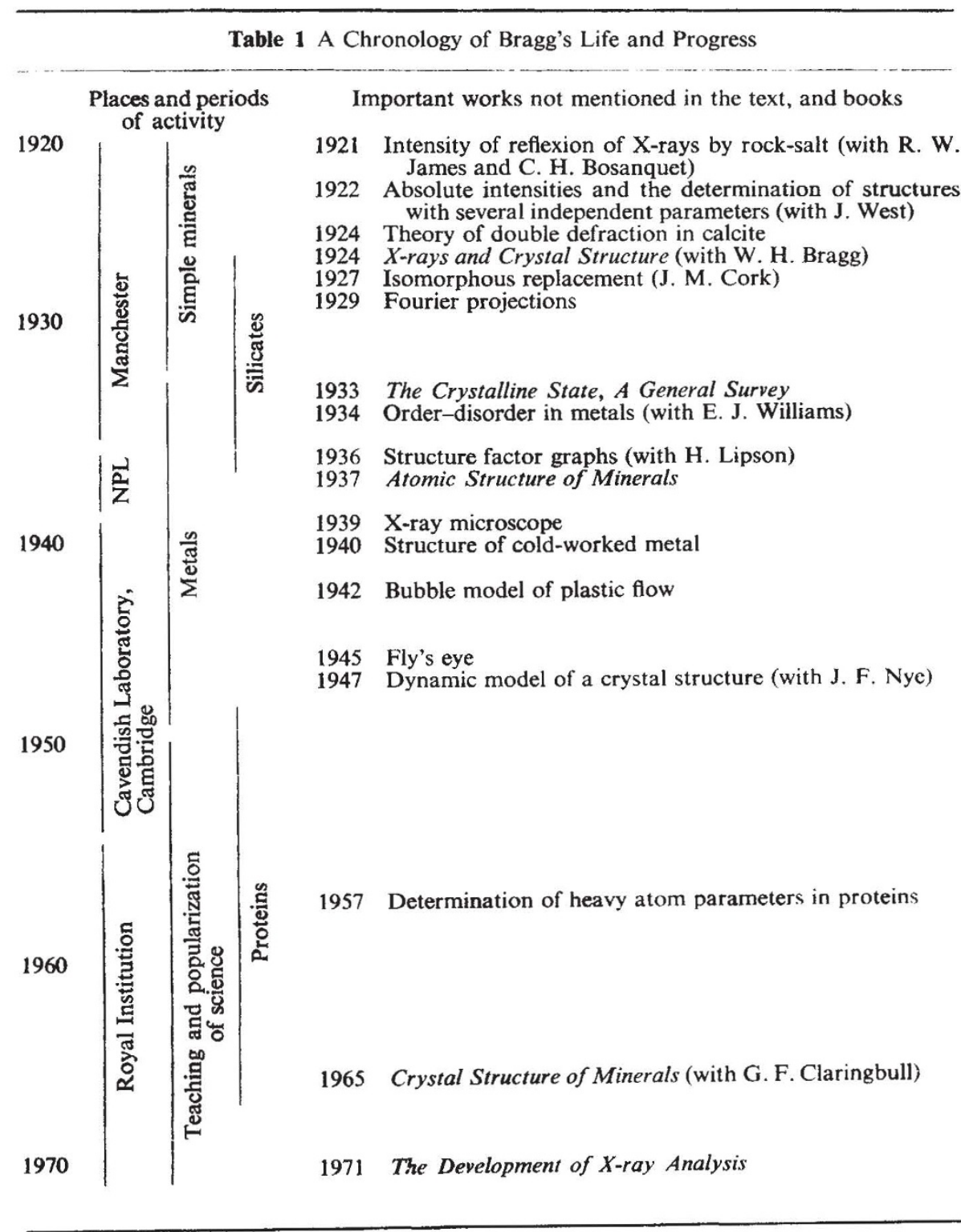


his latest roses. To the present young generation Bragg was an avuncular figure who showed them that science can be fun. At the Royal Institution he instituted a series of physics lectures for sixth formers, making use of the institution's excellent experimental facilities to bring home the laws of optics, electricity and magnetism. These lectures were attended by 22,000 London school children each year. He also gave a remarkable series of television broadcasts on the properties of matter which brought him popular fame. He was intrigued when the greengrocer woman in Soho told him that he was "the spitting image of a man she saw on the telly last night" and modestly signed the bill for her to keep as a souvenir. Bragg's superb powers of combining simplicity with rigour, his enthusiasm, liveliness and charm of manner, and his beautiful demonstrations all conspired to make him one of the best lecturers on science that ever lived. Yet few realized the formidable intellect that lay behind his genial façade or the decisive and revolutionary contributions to several fields of science for which he had been directly or indirectly responsible. His scientific papers still stand out as models of lucidity and conciseness. They generally contain little mathematics but are based on elegant physical and geometric arguments. His book on The Crystalline State once opened a new world to me and remains one of the best elementary introductions to X-ray crystallography.

Most X-ray crystallographers all over the world are "descended" from his or his father's pupils. He regarded them as one family and took the first steps in founding the International Union of Crystallography soon after the end of the Second World War. J. C. Kendrew's and my own early attempts at protein crystallography could not have been sustained throughout the many lean years without his support, and our small group at the Cavendish Laboratory in Cambridge became the nucleus from which the present MRC Laboratory of Molecular Biology later developed. Several other schools, including H. Lipson's at Manchester and W. Cochran's at Edinburgh, are offshoots of his group at the Cavendish. D. C. Phillips's flourishing Molecular Biophysics Laboratory at Oxford stems from the small protein crystallography group which Bragg brought together at the Royal Institution in the 1950s. We all owe him a great debt.

M. F. Perutz

\section{British Diary}

\section{Tuesday, September 7}

Computers for Analysis and Control in Medical and Biological Research (threeday conference) Institution of Electrical Engineers, in association with the Institute of Electrical and Electronics Engineers, the Institute of Mathematics and its Applications, the Institution of Electronic and Radio Engineers, the Biological Engineering Society and the British Computer Society, at the University of Sheffield.

Displays (four-day conference) Institution of Electrical Engineers; and the Institution of Electronic and Radio Engineers, at the University of Technology, Loughborough.

Human Locomotor Engineering (four-day conference) Institution of Mechanical Engineers, at the University of Sussex, Falmer, Brighton, Sussex.

\section{Thursday, September 9}

Electrical Plasmas as Free-Atom Generators, and Reservoirs for Analytical Atomic-Absorption, Emission and Fluorescent Spectroscopy (2.30 p.m.) Professor V. A. Fassel, Society for Analytical Chemistry, Midlands Region, at Henry Wiggin and Co., Ltd, Holmer Road, Hereford.

\section{Sunday, September 12}

Cell Nucleus (Third Harden Conference, six days) Biochemical Society in collaboration with the Biological Council, at Wye College, Ashford, Kent.

\section{Monday, September 13}

Fundamentals of Software for Computer Engineers (vacation school, thirteen days) Institution of Electrical Engineers, in association with the Institution of Electronic and Radio Engineers, at the University of Manchester.
Surface Chemistry of Oxides (three-day discussion) Faraday Society, in the Chemistry Department, Brunel University, Uxbridge, Middlesex.

\section{Reports and Publications}

not included in the Monthly Books Supplement

\section{Great Britain and Ireland}

West of Scotland Agricultural College, Grassland Husbandry Department. Experimental Records. No. 22: Comparison of Productivity of Eight Varieties of Cocksfoot. By I. V. Hunt, J. Frame and R. D. Harkess. Pp. 16. No. 23: Varietal Productivity. Meadow Fescue, Series II. By I. V. Hunt, J. Frame and R. D. Harkess. Pp. 15. No. 24: Comparison of Productivity of Varieties of Tall Fescue. By J. Frame, R. D. Harkess and I. B. Hunt. Pp. 45. No. 25: Comparison of Productivity of Varieties of Timothy. By I. V. Hunt, J. Frame and R. D. Harkess. Pp. 38. (Auchincruive, Ayr: West of Scotland Agricultural College, 1971.)

The Prospects for a European Security Conference. By Michael Palmer. (European Series, No. 18.) Pp. 107. (London: Chatham House and PEP, 1971.)
£1. The Birds of Exmoor. By N. V. Allen. Pp. $644+14$ plates. (Dulverton, Somerset: The Exmoor Press. 1971.) 50p. for for Mentally Handicapped People. Pp. 99. (London

\section{HOW TO BUY NATURE}

Volumes start in January, March, May, July, Septembe and November, but subscriptions may begin at any time.

The direct postal price per subscription is:

12 MONTHS * (52 issues per title)

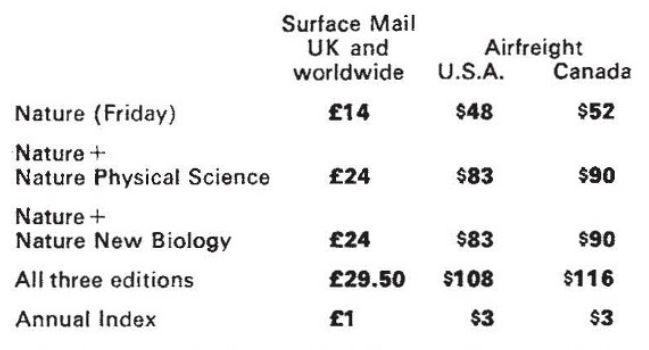

* Rates for shorter periods pro rata (minimum three months) (Charge for delivery by air mail on application)
Editorial and Publishing Offices of NATURE

MACMILLAN JOURNALS LIMITED

4 LITTLE ESSEX STREET, LONDON WC2R 3LF

Telephone Number : 01-836 6633. Telegrams : Phusis London WC2R 3LF 711 NATIONAL PRESS BUILDING WASHINGTON DC 20004

Telephone Number : 202-7372355 Subscription Department MACMILLAN JOURNALS LIMITED BRUNEL ROAD, BASINGSTOKE, HANTS

Telephone Number: Basingstoke 5431 American display advertisements NATURE SCIENTIFIC PUBLICATIONS INC 711 NATIONAL PRESS BUILDING WASHINGTON DC 20004 All other advertisements T. G. SCOTT \& SON, LIMITED 1 CLEMENT'S INN, LONDON WC2A 2ED Telephone : 01-242 6264/01-405 4743 Telegrams : Textualist London WC2A 2ED Registered as a newspaper at the Post Office Copyright (C) Macmillan Journals Limited, September 31971 